\title{
PENGARUH LEADER MEMBER EXCHANGE, EMPOWERMENT, TALENT MANAGEMENT TERHADAP TURNOVER INTENTION
}

\author{
I Made Prawira Aria Raharja ${ }^{1}$ \\ I Gusti Made Suwandana ${ }^{2}$ \\ ${ }^{1,2}$ Fakultas Ekonomi dan Bisnis Universitas Udayana, Bali, Indonesia \\ email:wiraaria23@gmail.com
}

\begin{abstract}
ABSTRAK
Tujuan dari penelitian ini untuk menguji pengaruh leader member exchange, empowerment, talent management terhadap turnover intention pada karyawan PT. BPR Tish di Kabupaten Gianyar. Sampel digunakan sebanyak 55 orang dengan metode sensus (total sampling), teknik analisis yang digunakan adalah regresi linear berganda. Hasil analisis diketahui leader member exchange berpengaruh positif dan signifikan terhadap turnover intention karyawan pada PT BPR Tish di Kabupaten Gianyar. Empowerment berpengaruh negatif dan signifikan terhadap turnover intention karyawan pada PT BPR Tish di Kabupaten Gianyar. Talent management berpengaruh negatif dan signifikan terhadap turnover intention karyawan pada PT BPR Tish di Kabupaten Gianyar. Saran untuk manajemen melakukan diskusi yang dipimpin oleh atasan dengan karyawan untuk menghadapi masalah-masalah yang terjadi diperusahan, sebagai pimpinan perusahaan harus mengajarkan karyawan untuk bekerja cerdas dan cepat dengan mengajarkan budaya kerja yang baik sehingga karyawan bekerja kembali dengan semangat. Perusahaan harus terus mengembangkan talent management sebagai dasar mendidik dan mengembangkan bakat karyawan. Manajemen PT BPR Tish dalam menghadapi masalah turnover intention karyawan banyak dipengaruhi oleh tingkat pendidikannya, ini yang perlu dievaluasi.
\end{abstract}

Kata kunci: leader member exchange, empowerment, talent management, turnover intention

\begin{abstract}
The purpose of this study to examine the influence of leader member exchange, empowerment, talent management to turnover intention on employees of PT. BPR Tish in Gianyar Regency. Sample used as many as 55 people with census method (total sampling), the analysis technique used is multiple linear regression. The result of analysis is known that member exchange leader has positive and significant impact to employee intention turnover at PT BPR Tish in Gianyar regency. Empowerment has a negative and significant effect on employee intention turnover at PT BPR Tish in Gianyar Regency. Talent management has a negative and significant effect on employee intention turnover at PT BPR Tish in Gianyar Regency. Suggestions for management conduct discussions led by employers with employees to deal with problems that occur in the company, as the company's leadership should teach employees to work smart and fast by teaching a good work culture so that employees work again with enthusiasm. Companies must continue to develop talent management as a foundation for educating and developing employee talents. The management of PT BPR Tish in facing the problem of employee turnover intention is much influenced by the level of education, this need to be evaluated.
\end{abstract}

Keywords: leader member exchange, empowerment, talent management, turnover intention 


\section{PENDAHULUAN}

Turnover karyawan adalah pengunduran diri permanen secara sukarela (voluntary) maupun tidak sukarela (involuntary) dari suatu organisasi (Robbins dan Judge, 2007:38). Voluntary turnover atau quit merupakan keputusan karyawan untuk meninggalkan organisasi secara sukarela, sebaliknya, involuntary turnover atau pemecatan menggambarkan keputusan pemberi kerja untuk menghentikan hubungan kerja dan bersifat uncontrollable bagi karyawan yang mengalaminya (Shaw et al., 1998) dalam Kharismawati dan Manuati (2016). Monica et al. (2015) memberi batasan turnover sebagai perpindahan karyawan dari pekerjaannya yang sekarang. Turnover dibutuhkan oleh perusahaan terhadap karyawan dengan kinerja rendah, namun tingkat turnover tersebut harus diupayakan agar tidak terlalu tinggi sehingga perusahaan masih memiliki kesempatan untuk memperoleh manfaat atau keuntungan atas peningkatan kinerja dari karyawan baru yang lebih besar dibanding biaya rekrutmen yang ditanggung organisasi (Aiza dan Abdus, 2013). Turnover yang tinggi berbahaya bagi perusahaan dan hal tersebut juga mengurangi efisiensi dan produktivitas organisasi (Azeez et al., 2016). Efek negatif tingginya tingkat turnover karyawan juga dapat menimbulkan pemborosan biaya yang cukup besar karena perusahaan harus menginvestasikan biaya untuk melakukan rekrutmen, orientasi, pelatihan, lembur, dan pengawasan (Iqra et al., 2014).

Bank Perkreditan Rakyat merupakan salah satu Bank di Indonesia yang hadir dan tumbuh sebagai bank yang mampu idealisme usaha dengan nilai-nilai rohani yang melandasi kegiatan operasinya. Salah satunya adalah BPR Tish di 
Kabupaten Gianyar yang memiliki misi untuk mewujudkan pertumbuhan dan keuntungan yang berkesinambungan dengan cara selalu berupaya untuk memastikan memberikan pelayanan dan kenyamanan bagi nasabah agar bisa mendapatkan nilai lebih dari sekedar kepuasan nasabah yang mereka dapatkan sampai diluar ruangan BPR. Sehingga kualitas pelayanan dan inovasi yang diberikan oleh BPR merupakan andalan mereka dalam memenangkan hati nasabah ditengah persaingan yang begitu kompetitif dalam dunia perbankkan saat ini, dengan jumlah karyawan sebanyak 56 orang. Jumlah karyawan yang paling dominan pada PT. BPR Tish terdapat pada bagian kredit dikarenakan sistem perusahaan menganut sistem perbankkan yang mendapatkan keuntungan dari penyaluran kredit ke nasabah sehingga membutuhkan tenaga pemasar yang cukup banyak. Ketidak berhasilan perusahaan atau instansi di dalam memperhatikan karyawan biasanya ditunjukkan dengan adanya indikasi terjadinya turnover karyawan (Titis et al., 2016).

Menurut Luthans (2011:44) turnover karyawan adalah suatu fenomena penting dalam kehidupan organisasi, faktor-faktor yang mempengaruhi seseorang untuk pindah kerja, yaitu karateristik kepemimpinan, peran management dan faktor pemberdayaan. Faktor kepemimpinan meliputi sikap dan pelaksanaan kepemimpinan sedangkan faktor peran management terbagi dua yaitu semua program yang ada dilakukan secara terintegrasi terhadap SDM. Pemberdayaan berperan strategis dalam mengembangkan kemampuan karyawan dengan pemberian wewenang sesuai tanggung jawab dalam melaksanakan pekerjaannya. 
Dasar pemikiran teori leader member exchange (LMX) adalah para pemimpin mengembangkan hubungan atasan-bawahan yang berbeda dengan masing-masing bawahan, seperti di dalam unit kerja, supervisor mengembangkan tipe hubungan yang berbeda dengan bawahannya. Sementara menurut Robbins (2011:359) Leader Member Exchange (LMX) dapat didefinisikan sebagai: "Penciptaan oleh para pemimpin dalam kelompok dan kelompok; dimana bawahan dibedakan dengan status kelompok yang memiliki peringkat kinerja lebih tinggi dengan kepuasan kerja yang lebih besar”. Sehubungan dengan definisi tersebut, dapat dilihat bahwa dalam LMX ditemukan perbedaan sikap yang diterima bawahan dari atasannya. Perbedaan itu membentuk kelompok terpisah yang menerangkan hubungan antara atasan dan bawahan yang disebut dengan in-group dan out-group (Robbins, 2011:368).

Mahmut et al. (2015) terdapat tiga domain menjadi dasar dalam membangun hubungan pada LMX yaitu respect, trust dan obligation. Hubungan antar atasan dan bawahan tidak dapat terbentuk tanpa adanya saling menghormati (respect) terhadap kemampuan orang lain, tanpa adanya rasa percaya yang timbal balik dengan yang lain, dan tidak memperkirakan bahwa pengaruh kewajiban akan berkembang menjadi suatu hubungan kerja (Muhammad et al., 2016).

Faktor lain yang mempengaruhi turnover intention karyawan salah satunya adalah empowerment. Empowerment atau pemberdayaan merupakan wewenang untuk membuat keputusan dalam suatu area kegiatan operasi tertentu tanpa harus memperoleh pengesahan orang lain (Luthans, 2011:78). Pemberdayaan adalah pemberian wewenang kepada karyawan untuk merencanakan (Planning), 
mengendalikan (Controlling) dan membuat keputusan atas pekerjaan yang menjadi tanggung jawabnya tanpa harus mendapatkan otorisasi secara eksplisit dari atasannya (Frans, 2015). Pemberdayaan merupakan alat yang dilakukan perusahaan sebagai rangsangan dalam meningkatkan motivasi serta menurunkan tingkat turnover intention karyawan (Rajkumar and Bhuvaneswari, 2016). Karyawan akan mengeluarkan semua potensi yang ada dalam dirinya melalui pemberdayaan sehingga meningkatkan motivasi terhadap perusahaan. Simon and Davey (2016) dalam penelitiannya menunjukkan lima aspek pemberdayaan psikologis memberikan dampak positif dan berkorelasi dengan motivasi intrinsik komitmen karyawan untuk menurunkan tingkat turnover intention karyawan (Vorya et al., 2013).

Talent management merupakan salah satu faktor yang mempengaruhi tingkat turnover intention karyawan di perusahaan. Penemuan talent management pada organisasi modern saat ini dirasakan sangat penting dikarenakan munculnya ekonomi modern dan kebutuhan bisnis yang semakin strategis (Liesl, 2010). Talent management merupakan serangkaian kegiatan yang dilakukan oleh perusahaan untuk mencari karyawan yang tepat serta menempatkan di tempat yang tepat melalui proses identifikasi, pengembangan, pertahanan, dan penempatan pada posisi yang sesuai (Zulkarnain, 2014). Aiza dan Abdus (2013) manajemen bakat (talent management) memiliki tujuan untuk membantu menurunkan turnover intention karyawan dan pengembangan karyawan dalam rangka memenuhi tantangan yang saat ini dihadapi oleh berbagai organisasi atau 
perusahaan dan meningkatkan performance organisasi melalui pemenuhan kebutuhan organisasi.

Sehubungan dengan hal diatas, maka turnover intention karyawan merupakan masalah yang sangat penting dalam suatu perusahaan, karena berdampak pada produktivitas perusahaan dalam meningkatkan laba. Sehingga kemampuan manajemen perlu didukung dengan sikap leader member exchange, pelaksanaan empowerment, dan talent management dalam melakukan pengawasan untuk menurunkan tingkat turnover intention karyawan, akan sangat menentukan keberhasilan atau kegagalan dalam pencapian tujuan perusahaan.

Melalui pemaparan masalah yang telah dijabarkan, didukung dengan karya ilmiah dan teori tujuan dari karya ilmiah ini yang hendak dicapai 1) Bagaimana pengaruh leader member exchange terhadap turnover intention karyawan PT.BPR Tish di Kabupaten Gianyar, 2) Bagaimana pengaruh empowerment terhadap turnover intention karyawan PT.BPR Tish di Kabupaten Gianyar, 3) Bagaimana pengaruh talent management terhadap turnover intention karyawan PT.BPR Tish di Kabupaten Gianyar.

Teori atribusi (attribution theory) teori atribusi memberikan penjelasan tentang proses bagaimana kita menentukan penyebab/ motif perilaku seseorang (Robbins and Judge, 2007). Teori ini diarahkan untuk mengembangkan penjelasan dengan cara-cara kita menilai orang secara berlainan, tergantung makna apa yang akan kita hubungkan (atribusikan) ke suatu perilaku tertentu. Teori atribusi itu sendiri, mengacu pada bagaimana seseorang menjelaskan penyebab perilaku orang lain/diri sendiri, yang ditentukan apakah dari faktor 
internal/ eksternal, maka akan terlihat pengaruhnya terhadap perilaku individu. Penyebab perilaku dikenal sebagai dispositional attributions dan situational attributions atau penyebab internal dan eksternal (Robbins, 2011: 61). Dispositional attribution atau penyebab internal mengacu pada aspek perilaku individual, sesuatu yang ada dalam diri seseorang seperti sifat pribadi, persepsi diri, kemampuan dan motivasi. Situational attributions atau penyebab eksternal mengacu pada lingkungan tempat kerja yang mempengaruhi perilaku, seperti kondisi sosial, nilai sosial, fungsi manajemen, sikap kepemimpinan, dan pandangan masyarakat.

Turnover Intention dapat diartikan sebagai pergerakan tenaga kerja keluar dari organisasi. Turnover menurut Robbins dan Judge (2007:38) adalah tindakan pengunduran diri secara permanen yang dilakukan oleh karyawan baik secara sukarela ataupun tidak secara sukarela. Turnover dapat berupa pengunduran diri, perpindahan keluar unit organisasi, pemberhentian atau kematian anggota organisasi. Jochan (2015) menyebutkan turnover intention merupakan prediktor terbaik untuk mengindentifikasi perilaku turnover yang akan terjadi pada karyawan suatu organisasi.

Robbins (2011: 181-182) menyatakan indikator-indikator yang mempengaruhi terjadinya turnover cukup kompleks dan saling berkaitan satu sama lain. Diantara indikator-indikator tersebut yang akan dibahas antara lain sebagai berikut.

Usia, tingkat turnover yang cenderung lebih tinggi pada karyawan berusia muda disebabkan karena mereka memiliki keinginan untuk mencoba-coba 
pekerjaan atau organisasi kerja serta ingin mendapatkan keyakinan diri lebih besar melalui cara coba-coba tersebut.

Lama kerja, semakin lama masa kerja semakin rendah kecenderungan turnovernya. Turnover lebih banyak terjadi pada karyawan dengan masa kerja lebih singkat. Interaksi dengan usia, kurangnya sosialisasi awal merupakan keadaan-keadaan yang memungkinkan turnover tersebut. Turnover terjadi karena rendahnya pelaksanaan talent management dengan kurangnya sosialisasi yang dilaksanakan perusahaan terhadap karyawan.

Tingkat pendidikan dan intellegensi, karyawan yang mempunyai tingkat intellegensi tidak terlalu tinggi akan memandang tugas-tugas yang sulit sebagai tekanan dan sumber kecemasan yang disebut dengan out-group. Sebaliknya mereka yang mempunyai tingkat intellegensi yang lebih tinggi akan merasa cepat bosan dengan pekerjaan-pekerjaan yang monoton yang sangat erat berhubungan dengan leader member exchange yaitu in-group.

Keterikatan terhadap perusahaan, pekerja yang mempunyai rasa keterikatan yang kuat terhadap perusahaan tempat ia bekerja berarti mempunyai dan membentuk perasaan memiliki (sense of belonging), rasa aman, efikasi, tujuan dan arti hidup serta gambaran diri positif. Akibat secara langsung adalah menurunnya dorongan diri untuk berpindah pekerjaan dan perusahaan..

Pengertian leader member exchange (LMX) sebagaimana pendapat Robbins (2011:198) bahwa "leader member exchange merupakan peningkatan kualitas hubungan antara supervisi dengan karyawan akan mampu meningkatkan kerja keduanya. Namun realitasnya, hubungan antara karyawan dan supervisi 
dapat dikelompokkan pada dua hubungan yaitu hubungan yang baik dan hubungan yang buruk. Hubungan yang baik akan menciptakan kepercayaan karyawan, sikap positif, dan loyalitas, namun hubungan yang buruk berpengaruh sebaliknya.

Indikator variabel leader member exchange menurut Mahmut et al. (2015) terdapat tiga indikator leader member exchange, yaitu : Respect, Hubungan antar atasan dan bawahan tidak dapat terbentuk tanpa adanya saling menghormati (respect) terhadap kemampuan orang lain. Trust, tanpa adanya rasa percaya yang timbal balik, hubungan antara atasan dengan bawahan akan sulit terbentuk. Obligation, pengaruh kewajiban akan berkembang menjadi suatu hubungan kerja antara atasan dengan bawahan.

Robbins (2011:175) menyatakan pemberdayaan merupakan menempatkan pekerjaan bertanggung jawab atas apa yang mereka kerjakan. Memberdayakan orang berarti mendorong mereka menjadi lebih terlibat dalam keputusan dan aktivitas yang mempengaruhi pekerjaan mereka (Vorya et al., 2013). Seorang karyawan memiliki wewenang dan berinisiatif untuk melakukan sesuatu yang dipandang perlu, jauh melebihi tugasnya sehari-hari (Davey, 2016). Pemberdayaan merupakan wewenang untuk membuat keputusan dalam suatu area kegiatan operasi tertentu tanpa harus memperoleh pengesahan orang lain (Luthans, 2011). Empat karakteristik umum yang dimiliki empowered people tersebut adalah sebagai berikut.

Sense of meaning, meaning merupakan nilai tujuan pekerjaan yang dilihat dari hubungannya pada idealisme atau standar individu. Sense of competence, 
kompetensi atau self-efficacy merupakan kepercayaan individu akan kemampuan mereka dalam melakukan aktivitas mereka dengan menggunakan keahlian yang mereka miliki. Sense of self-determination, bila kompetensi merupakan keahlian dalam perilaku, maka self determination merupakan suatu perasaan memiliki suatu pilihan dalam membuat pilihan dan melakukan suatu pekerjaan. Sense of impact, impact atau dampak merupakan derajat dimana seseorang dapat mempengaruhi hasil pekerjaan baik strategik, administratif, maupun operasional.

Model pemberdayaan yang dapat dikembangkan dalam sebuah organisasi untuk menjamin keberhasilan proses pemberdayaan dalam suatu organisasi (Japie et al., 2011). Model pemberdayaan tersebut adalah desire, tahap pertama dalam model pemberdayaan adalah adanya keinginan manajemen untuk mendelegasikan dan melibatkan pekerja. Trust, tahap yang kedua adalah membangun kepercayaan antara manajemen dan karyawan. Confident, tahap yang ketiga dalam proses pemberdayaan adalah menimbulkan rasa percaya diri karyawan dan menghargai terhadap kemampuan yang dimiliki oleh karyawan. Credibility, tahap yang keempat adalah menjaga kredibilitas dengan penghargaan dan mengembangkan lingkungan kerja yang sehat sehingga tercipta organisasi yang memiliki performance yang tinggi (Natalia et al., 2010). Accountability, tahap kelima dalam proses pemberdayaan adalah pertanggung jawaban karyawan pada wewenang yang diberikan. Communication, tahap keenam atau terakhir dalam pemberdayaan adalah komunikasi yang terbuka untuk menciptakan rasa saling memahami antara karyawan dengan manajemen (Sehresh and Maryam, 2015). 
Robbins (2011:106) menjelaskan bahwa, talent management adalah sebuah langkah untuk memastikan penempatan posisi kunci pemimpin masa depan yang tepat pada perusahaan (organizational future leaders) dan posisi yang mendukung kelangsungan kompetensi inti perusahaan yaitu karyawan yang memiliki skill yang dibutuhkan serta memiliki strategi tinggi untuk pencapaian tujuan perusahaan. Plessis (2015) menyatakan bahwa, talent management berkaitan dengan perekrutan kandidat perusahaan yang tepat dengan skill yang tepat untuk ditempatkan pada bidang yang sesuai. Setiap personal individu memiliki skill yang berbeda satu dengan yang lainnya. Peran serta tanggung jawab yang cukup sulit bagi manajemen perusahaan adalah mengidentifikasi SDM yang cocok dengan culture organisasi yang ada.

Terdapat enam perspektif indikator yang diidentifikasi dalam membentuk organisasi dengan pendekatan talent management (Aiza dan Abdus, 2013) yaitu perspektif kompetitif (the competitive perspective), perspektif ini memandang bahwa talent management harus mengidentifikasi orang-orang berbakat serta memberikan apa yang mereka inginkan, jika tidak mereka akan diburu oleh para pesaing. Perspektif proses (the process perspective), perspektif ini memandang bahwa talent management terdiri dari berbagai proses yang dilakukan untuk mendukung pengoptimalisasian individu pada suatu organisasi. Perspektif perencanaan SDM (the HR planning perspective), perspektif ini mirip dengan perspektif proses tetapi lebih memfokuskan pada orientasi SDM untuk mencocokkan orang yang tepat untuk pekerjaan yang tepat pada waktu yang tepat dan melakukan hal yang benar. Perspektif pengembangan (the developmental 
perspective), perspektif ini fokus terhadap pengembangan potensi yang tinggi maupun pengembangan bakat yang lebih cepat dari pada yang lainnya. Perspektif budaya (the culture perspective), perspektif ini memadang bahwa setiap individu akan sukses jika mereka memiliki talent yang cukup dan kesuksesan bisnis akan mengikuti kesuksesan-kesuksesan mereka. Perspektif manajemen perubahan (the change manajemen perspective), perspektif ini melihat bahwa talent management dipandang sebagai pendorong perubahan, dimana karyawan merasa manajemen mendorong untuk berubah kearah yang lebih baik.

Beberapa penelitian menyatakan leader member exchange memiliki pengaruh terhadap turnover intention karyawan. Penelitian Titiksa dan Artha (2016) menyatakan leader member exchange memiliki pengaruh positif terhadap turnover intention karyawan. Kenneth et al. (2009) menyatakan variabel leader member exchange memberikan pengaruh positif dalam meningkatkan turnover intention karyawan. Mahmut et al. (2015) membuktikan hal yang sama leader member exchange secara langsung memberikan pengaruh positif terhadap turnover intention karyawan. Dipertegas oleh Muhammad et al. (2016) variabel leader member exchange secara langsung memberikan pengaruh positif terhadap turnover intention karyawan. Berdasarkan pemahaman tersebut dapat dirumuskan hipotesis pertama sebagai berikut.

$\mathrm{H}_{1}$ : leader member exchange berpengaruh positif terhadap turnover intention.

Beberapa penelitian menyatakan empowerment atau pemberdayaan memiliki pengaruh dalam menurunkan tingkat turnover intention karyawan. Penelitian Rajkumar and Bhuvaneswari (2016) menyatakan empowerment atau 
pemberdayaan memiliki pengaruh negatif terhadap turnover intention karyawan. Vorya et al. (2013) menyatakan variabel empowerment memberikan pengaruh positif dalam menurunkan tingkat turnover intention karyawan. Davey (2016) membuktikan hal yang sama empowerment yang diberikan kepada karyawan secara langsung memberikan pengaruh positif terhadap penurunan turnover intention. Dipertegas oleh Frans (2015) variabel empowerment secara langsung memberikan pengaruh negatif terhadap turnover intention. Berdasarkan pemahaman tersebut dapat dirumuskan hipotesis kedua sebagai berikut.

$\mathrm{H}_{2}$ : empowerment berpengaruh negatif terhadap turnover intention karyawan. Penelitian Aiza dan Abdus (2013) menyatakan talent management memiliki pengaruh positif terhadap penurunan turnover intention karyawan. Liesl (2010) menyatakan variabel talent management memberikan pengaruh negatif terhadap turnover intention karyawan. Urbancová and Vnoučková (2015) membuktikan hal yang sama talent management yang diberikan kepada karyawan secara langsung memberikan pengaruh positif terhadap penurunan turnover intention karyawan. Dipertegas oleh Munish and Rachna (2017) variabel talent management secara langsung memberikan pengaruh positif terhadap penurunan turnover intention karyawan. Berdasarkan pemahaman tersebut dapat dirumuskan hipotesis pertama sebagai berikut.

$\mathrm{H}_{3}$ : talent management berpengaruh negatif terhadap turnover intention. 


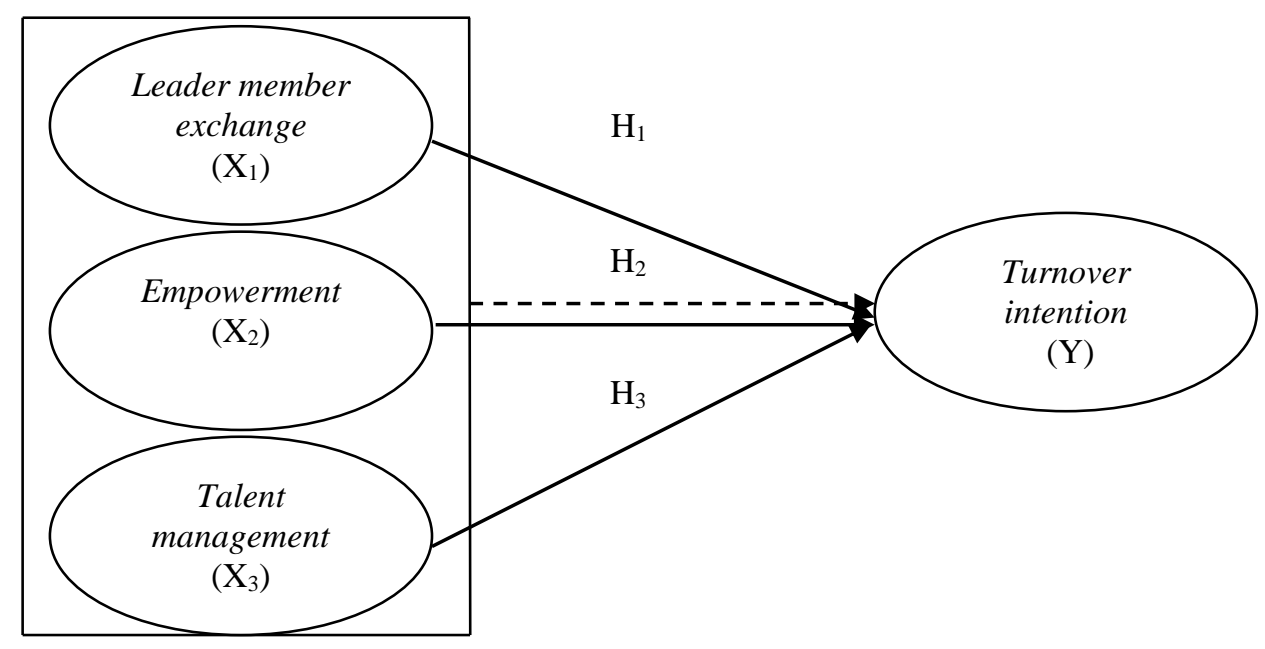

Gambar 1. Kerangka Konseptual

\section{METODE PENELITIAN}

Karya ilmiah ini menggunakan metode asosiatif yang bertujuan untuk mengetahui pengaruh ataupun juga hubungan antara dua variabel atau lebih (Sugiyono, 2013:56). Penelitian ini dilakukan di PT. Bank Perkreditan Rakyat Tish Gianyar, yang beralamat di Jln. Raya Batubulan No. 27X Kecamatan Sukawati, Kabupaten Gianyar. Adapun alasan yang melatarbelakangi melakukan penelitian ini mengingat pada perusahaan ini terdapat masalah yang terjadi menyangkut tingginya turnover intention karyawan dalam pelaksanaan dan penyelesaian pekerjaan yang mengindikasikan masih minimnya pelaksanaan empowerment dan talent management oleh perusahaan terhadap karyawan. Masih terdapat karyawan yang mengeluh karena serta sikap pimpinan yang mengacu pada leader member exchange mengesankan pengelompokkan karyawan.

Obyek penelitian adalah suatu hal atau apa saja yang menjadi perhatian dan apa saja yang diteliti (kamus bahasa Indonesia, 2008). Sebagai obyek dalam 
penelitian adalah leader member exchange, empowerment, talent management terhadap turnover intention karyawan PT. BPR Tish. Variabel bebas adalah Leader member exchange $\left(\mathrm{X}_{1}\right)$, Empowerment $\left(\mathrm{X}_{2}\right)$, Talent management $\left(\mathrm{X}_{3}\right)$ dan variabel terikat adalah turnover intention $(\mathrm{Y})$.

Jenis data kuantitatif dan kualitatif yang dipergunakan seperti data jumlah karyawan, jawaban responden terhadap kuisioner dan seperti sejarah perusahaan, struktur organisasi dan aktivitas perusahaan. Sumber data primer dan sekunder yang dipergunakan seperti observasi dan pemberian kuesioner kepada responden dan sejarah berdirinya perusahaan, struktur organisasi perusahaan, dan jumlah karyawan.

Jumlah sampel adalah karyawan di PT. BPR Tish sebanyak 55 orang tidak termasuk manager yang di klasifikasikan berdasarkan metode sampel jenuh (Sugiyono, 2013:85). Data yang dikumpulkan dalam penelitian ini menggunakan metode wawancara, pustaka dan kuesioner yang diberikan kepada responden yang telah dipilih.

Uji validitas menyatakan sebuah instrumen dikatakan valid jika item yang mempunyai korelasi positif dengan kriterum (skor total) serta korelasi tinggi menunjukkan bahwa item tersebut mempunyai validitas yang tinggi pula. Syarat minimum untuk dianggap memenuhi syarat adalah kalau $r=0,3$ ". Uji reabilitas ditunjukkan dengan angka indeks yang konsistensi suatu alat ukur dalam mengukur gejala yang sama. Uji reabilitas mampu menunjukan sejauh mana instrument dapat dipercaya dan diharapkan. Nilai suatu instrumen dikatakan reliabel bila nilai Alpha Cronbach $\geq 0,6$. 
Data yang dikumpulkan dalam penelitian ini akan dianalisis dengan cara regresi linier berganda, untuk menduga arah dari hubungan variabel bebas dengan variabel terikat tersebut serta mengukur derajat keeratan hubungan antara satu variabel terikat. Adapun bentuk umum dari persamaan regresi linier berganda menurut (Suyana, 2016:93) sebagai berikut.

$$
\mathrm{Y}=\alpha+\beta_{1} X_{1}+\beta_{2} X_{2}+\beta_{3} X_{3}+\mu i
$$

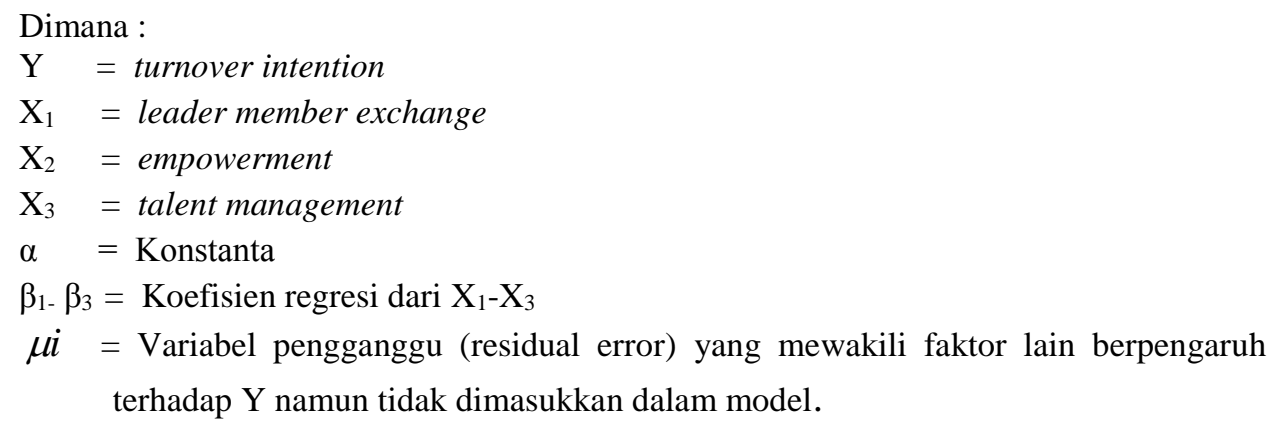

Karena dalam penelitian ini menggunakan statistik parametrik dengan model regresi berganda, maka sebelumnya perlu dilakukan uji asumsi klasik meliputi uji normalitas, uji heteroskedastisitas, dan uji multikolinearitas.

Untuk menguji ketepatan model regresi pengaruh variabel bebas leader member exchange $\left(\mathrm{X}_{1}\right)$, empowerment $\left(\mathrm{X}_{2}\right)$, talent management $\left(\mathrm{X}_{3}\right)$ secara serempak terhadap variabel terikat turnover intention $(\mathrm{Y})$. Uji hipotesis (t-test) bertujuan untuk menguji signifikansi pengaruh variabel leader member exchange $\left(\mathrm{X}_{1}\right)$, empowerment $\left(\mathrm{X}_{2}\right)$, talent management $\left(\mathrm{X}_{3}\right)$ secara parsial terhadap variabel terikat turnover intention $(\mathrm{Y})$. 


\section{HASIL DAN PEMBAHASAN}

Tabel 1.

Rangkuman Hasil Uji Validitas

\begin{tabular}{|c|c|c|c|c|}
\hline No & Variabel & Indikator & Korelasi & Keterangan \\
\hline \multirow{3}{*}{1} & \multirow{3}{*}{ Leader member exchange $\left(\mathrm{X}_{1}\right)$} & $\mathrm{X} 1.1$ & 0,920 & Valid \\
\hline & & $\mathrm{X} 1.2$ & 0,738 & Valid \\
\hline & & $\mathrm{X} 1.3$ & 0,880 & Valid \\
\hline \multirow{4}{*}{2} & \multirow{4}{*}{ Empowerment $\left(\mathrm{X}_{2}\right)$} & $\mathrm{X} 2.1$ & 0,895 & Valid \\
\hline & & $\mathrm{X} 2.2$ & 0,724 & Valid \\
\hline & & $\mathrm{X} 2.3$ & 0,867 & Valid \\
\hline & & $\mathrm{X} 2.4$ & 0,868 & Valid \\
\hline \multirow{6}{*}{3} & \multirow{6}{*}{ Talent management $\left(\mathrm{X}_{3}\right)$} & $\mathrm{X} 3.1$ & 0,825 & Valid \\
\hline & & X3.2 & 0,834 & Valid \\
\hline & & $\mathrm{X} 3.3$ & 0,678 & Valid \\
\hline & & X3.4 & 0,756 & Valid \\
\hline & & $\mathrm{X} 3.5$ & 0,868 & Valid \\
\hline & & X3.6 & 0,777 & Valid \\
\hline \multirow{4}{*}{4} & \multirow{4}{*}{ Turnover intention $(\mathrm{Y})$} & Y1 & 0,896 & Valid \\
\hline & & $\mathrm{Y} 2$ & 0,847 & Valid \\
\hline & & Y3 & 0,890 & Valid \\
\hline & & Y4 & 0,920 & Valid \\
\hline
\end{tabular}

Sumber: Data diolah, 2018

Tabel 1 diketahui bahwa masih-masing indikator variabel memiliki nilai person correlation lebih besar dari 0,30, maka ini berarti indikator/pertanyaan yang digunakan layak digunakan untuk mengukur apa yang seharusnya diukur, dan dapat mengungkap data dari variabel yang diteliti secara tepat.

Tabel 2.

Hasil Uji Reliabilitas

\begin{tabular}{clcc}
\hline No & \multicolumn{1}{c}{ Variabel } & Cronbach's Alpha & Keterangan \\
\hline 1 & Leader member exchange $\left(\mathrm{X}_{1}\right)$ & 0,800 & Reliabel \\
2 & Empowerment $\left(\mathrm{X}_{2}\right)$ & 0,859 & Reliabel \\
3 & Talent management $\left(\mathrm{X}_{3}\right)$ & 0,875 & Reliabel \\
4 & Turnover intention $(\mathrm{Y})$ & 0,910 & Reliabel \\
\hline
\end{tabular}

Sumber: Data diolah, 2018 
Tabel 2 diketahui bahwa nilai Cronbach's Alpha untuk masing-masing variabel $>0,6$, ini berarti alat ukur tersebut akan memberikan hasil yang konsisten apabila alat ukur tesebut digunakan kembali untuk meneliti obyek yang sama.

Hasil analisis regresi linear berganda bertujuan untuk mengetahui pegaruh leader member exchange, empowerment, talent management terhadap turnover intention yang dapat dilihat pada Tabel 3 berikut ini.

Tabel 3.

Rangkuman Hasil Analisis Regresi Linear Berganda

\begin{tabular}{|c|c|c|c|c|c|}
\hline \multirow{2}{*}{ Variabel } & & \multicolumn{2}{|c|}{ Koefisien Regresi } & \multirow[b]{2}{*}{$\mathbf{t}$} & \multirow{2}{*}{ Sig } \\
\hline & & B & Std. error & & \\
\hline (constant) & & 23.381 & 2.830 & & \\
\hline Leader member exchange & & 0.366 & .126 & 2.915 & .005 \\
\hline Empowerment & & -0.368 & .175 & -2.100 & .041 \\
\hline Talent management & & -0.281 & .130 & -2.163 & .035 \\
\hline Dependen variabel & : & turnover intention & & & \\
\hline F Statistik & : & 68.940 & & & \\
\hline Sig F & : & 0.000 & & & \\
\hline $\mathrm{R}^{2}$ & : & 0.802 & & & \\
\hline
\end{tabular}

Sumber: Data diolah, 2018

Berdasarkan Tabel 3 dapat ditulis persamaan regresi linear berganda sebagai berikut.

$$
Y=23,381+0,366 X_{1}-0,368 X_{2}-0,281 X_{3}
$$

Pengujian ini menunjukkan hasil perhitungan regresi linear berganda yang bahwa $F_{\text {hitung }}=68,940$ dan nilai $F_{\text {tabel }}$ dengan tingkat keyakinan $95 \%$ dan $\alpha=0,05$; df $=(k-1):(n-k)=(3: 51)$ adalah sebesar 2,76. Oleh karena $F_{\text {hitung }}(68,940)$ lebih besar dari $F_{\text {tabel }}(2,76)$ dengan nilai signifikansi $0,000<0,05$ maka dapat disimpulkan leader member exchange, empowerment, talent management berpengaruh signifikan secara simultan terhadap turnover intention. 
Uji normalitas akan ditampilkan pada Tabel 4 hasil yang didapatkan dengan menggunakan uji Kolmogorov-Smirnov dengan signifikansi lebih besar dari 0,05 yaitu 0,497 maka dapat disimpulkan bahwa model regresi terdistribusi secara normal.

Tabel 4.

Hasil Uji Kolmogorov-Smirnov

\begin{tabular}{llr}
\hline & & Unstandardized Residual \\
\hline $\mathrm{N}$ & & 55 \\
Normal Parameters(a,b) & Mean & 1.0205 \\
& Std, Deviation & .75097 \\
Most Extreme Differences & Absolute & .112 \\
& Positive & .112 \\
& Negative & -.091 \\
& & .829 \\
Kolmogorov-Smirnov Z & & .497 \\
Asymp. Sig. (2-tailed) & &
\end{tabular}

Berdasarkan hasil pengujian multikolinearitas diketahui nilai VIF (Varian Inflatation Factor) tidak lebih dari 10 dan mempunyai angka tolerance tidak kurang dari 0,1, maka ini berarti dalam model regresi tidak terjadi multikolinearitas yang dapat dilihat pada Tabel 5 berikut.

Tabel 5.

Hasil Uji Multikolinearitas

\begin{tabular}{clcc}
\hline \multirow{2}{*}{ No } & \multirow{2}{*}{ Model } & \multicolumn{2}{c}{ Collinearity Statistic } \\
& & Tolerance & VIF \\
\hline 1 & Leader member exchange & 0.480 & 2.084 \\
2 & Empowerment & 0.152 & 6.593 \\
3 & Talent management & 0.134 & 7.455 \\
\hline
\end{tabular}

Sumber: Data diolah, 2018

Berdasarkan hasil pengujian heteroskedastisitas dapat dilihat bahwa hampir semua variabel memiliki nilai sig $>0,05$ ini berarti pada model regresi tidak terjadi gejala heteroskedasitisitas yang dapat dilihat pada Tabel 6 berikut. 
Tabel 6.

\begin{tabular}{|c|c|c|c|c|c|c|}
\hline \multirow[t]{2}{*}{ Model } & & \multicolumn{2}{|c|}{$\begin{array}{l}\text { Unstandardized } \\
\text { Coefficients }\end{array}$} & \multirow{2}{*}{$\begin{array}{l}\text { Standardized } \\
\text { Coefficients } \\
\text { Beta }\end{array}$} & \multirow[t]{2}{*}{$\mathbf{t}$} & \multirow[t]{2}{*}{ Sig. } \\
\hline & & B & Std. Error & & & \\
\hline 1 & (Constant) & -1.209 & 1.607 & & -.752 & .455 \\
\hline 2 & $\begin{array}{l}\text { Leader member } \\
\text { exchange }\end{array}$ & -.011 & .071 & .230 & 1.159 & .244 \\
\hline 3 & Empowerment & .028 & .099 & -.434 & -1.253 & .216 \\
\hline 4 & $\begin{array}{l}\text { Talent } \\
\text { management }\end{array}$ & .028 & .074 & .685 & 1.858 & .069 \\
\hline
\end{tabular}

Sumber: Data diolah, 2018

Pengaruh tiap-tiap variabel bebas dalam model ini digunakan untuk mengetahui pengaruh variabel bebas, yaitu leader member exchange $\left(\mathrm{X}_{1}\right)$, empowerment $\left(\mathrm{X}_{2}\right)$, talent management $\left(\mathrm{X}_{3}\right)$ secara parsial terhadap turnover intention (Y) dapat dilihat pada Tabel 7.

Tabel 7.

\section{Hasil Analisis Uji t-test}

\begin{tabular}{ccccc}
\hline Variabel & thitung & tabel & Hasil Uji t & Hasil Hipotesis \\
\hline $\mathrm{X}_{1}$ & 2,915 & 1,671 & $(2,915)>(1,671)$ & $\mathrm{H}_{0}$ ditolak \\
$\mathrm{X}_{2}$ & $-2,100$ & 1,671 & $(-2,100)>(1,671)$ & $\mathrm{H}_{0}$ ditolak \\
$\mathrm{X}_{3}$ & $-2,163$ & 1,671 & $(-2,163)>(1,671)$ & $\mathrm{H}_{0}$ ditolak \\
\hline
\end{tabular}

Sumber: Data diolah, 2018

Hasil analisis data menunjukkan leader member exchange memberikan pengaruh positif terhadap turnover intention karyawan pada PT BPR Tish di Kabupaten Gianyar, Robbins (2011:105) mengungkapkan bahwa semakin baik penerapan leader member exchange di dalam perusahaan diyakini dapat menekan terjadinya turnover intention karyawan. Sebaliknya, apabila leader member exchange dalam di dalam perusahaan tersebut yang berpihak kepada satu kelompok, maka akan meningkatkan dampak turnover intention karyawan 
sehingga menyebabkan menurunnya prestasi kerja karyawan itu sendiri di dalam melaksanakan pekerjaannya (Alean, 2014).

Beberapa penelitian menyatakan leader member exchange memiliki pengaruh terhadap turnover intention karyawan. Penelitian Titiksa dan Artha (2016) menyatakan leader member exchange memiliki pengaruh positif terhadap turnover intention karyawan. Kenneth et al. (2009) menyatakan variabel leader member exchange memberikan pengaruh positif dalam meningkatkan turnover intention karyawan. Mahmut et al. (2015) membuktikan hal yang sama leader member exchange secara langsung memberikan pengaruh positif terhadap turnover intention karyawan.

Hasil analisis data menunjukkan empowerment memberikan pengaruh negatif terhadap turnover intention karyawan pada PT BPR Tish di Kabupaten Gianyar, Robbins (2011: 98) menegaskan pemberdayaan merupakan alat yang dilakukan perusahaan sebagai rangsangan dalam menurunkan tingkat turnover intention karyawan. Semakin baiknya pelaksanaan pemberdayaan diperusahaan akan mampu menurunkan tingkat turnover intention karyawan dan sebaliknya (Fedelis, 2014).

Beberapa penelitian menyatakan empowerment atau pemberdayaan memiliki pengaruh dalam menurunkan tingkat turnover intention karyawan. Penelitian Rajkumar and Bhuvaneswari (2016) menyatakan empowerment atau pemberdayaan memiliki pengaruh negatif terhadap turnover intention karyawan. Vorya et al. (2013) menyatakan variabel empowerment memberikan pengaruh positif dalam menurunkan tingkat turnover intention karyawan. Davey (2016) 
membuktikan hal yang sama empowerment yang diberikan kepada karyawan secara langsung memberikan pengaruh positif terhadap penurunan turnover intention.

Hasil analisis data menunjukkan talent management memberikan pengaruh negatif terhadap turnover intention karyawan pada PT BPR Tish di Kabupaten Gianyar, Rivai (2006:217) menyatakan setiap perusahaan selalu mengharapkan karyawan dengan talent management mampu bekerja dengan baik. Karyawan yang memiliki talenta yang baik bila di dukung dengan pelaksaan talent management akan mampu menurunkan turnover intention di dalam perusahaan (Munish and Rachna, 2017).

Beberapa penelitian menyatakan talent management memiliki pengaruh terhadap turnover intention karyawan. Penelitian Aiza dan Abdus (2013) menyatakan talent management memiliki pengaruh positif terhadap penurunan turnover intention karyawan. Liesl (2010) menyatakan variabel talent management memberikan pengaruh negatif terhadap turnover intention karyawan.

\section{Implikasi Penelitian}

Teori Leader-Member Exchange terletak pada asumsi bahwa pemimpin mempengaruhi karyawan dalam kelompok mereka (disebut sebagai anggota) melalui kualitas hubungan yang baik ataupun tidak baik, hubungan kualitas tinggi yang ditandai dengan kepercayaan, keinginan, rasa hormat, profesional, dan loyalitas. Teori LMX adalah sebagai gagasan bahwa pemimpin memperlakukan bawahan mereka berbeda dengan kualitas pertukaran sosial di antara mereka. Berbagai hal yang harus dilakukan dalam hal ini untuk menekan 
terjadinya turnover intention pada karyawan dengan pelaksanaan Leader-Member Exchange secara berkesinambungan sehingga memberikan peran aktif pada karyawan dengan menunjukkan kualitas hubungan yang baik dan harmonis sehingga mampu memberikan yang terbaik untuk perusahaan kedepan.

Proses turnover pada dasarnya diawali oleh suatu kondisi yang disebut turnover intention atau keinginan karyawan untuk keluar dari perusahaan. Turnover intention merupakan faktor yang menentukan actual turnover dari suatu perusahaan sehingga perlu suatu tindakan untuk mengatasinya, salah satunya dengan melaksanakan pemberdayaan karyawan. Employee empowerment dapat dilaksanakan dengan pelatihan yang perlu diadakan agar dapat lebih meningkatkan dampak dari penyelenggaraan perusahaan. Employee empowerment yang telah dilakukan akan menjadi stimulus dalam membentuk persepsi employee empowerment yang meliputi 2 perspektif yaitu psychological empowerment dan organizational empowerment sehingga mampu menekan terjadinya perilaku turnover intention.

Dalam suatu organisasi diperlukan keinginan untuk lebih maju lagi dari pada karyawan, sehingga akan lebih memudahkan untuk memasukin pasar global. Dengan tingginya tingkat turnover pada karyawan akan membuat kekhawatiran dari citra organisasi. Hal ini tentunya dapat diatasi dengan menerapkan talent management. Talent management yang dapat dilakukan pada suatu organisasi dilaksanakan dengan memberikan pengarahan terhadap proses pengembangan dan pemanfaatan kemampuan, keahlian serta talenta yang dimiliki karyawan. Manajemen talenta merupakan pendekatan korporat yang terencana dan 
terstruktur untuk merekrut, mempertahankan dan mengembangkan orang-orang bertalenta dalam organisasi. Sistem manajemen talenta yang dilaksanakan ini bertujuan untuk menyiapkan sumber daya manusia yang handal dalam jumlah yang memadai untuk menempati posisi-posisi kunci perusahaan sehingga keberlangsungan bisnis perusahaan dapat terjamin.

\section{Keterbatasan Penelitian}

Penelitian ini hanya meneliti tentang beberapa variabel leader member exchange, empowerment, talent management dalam mengukur turnover intention, kedepan agar dibandingkan dengan memilih variabel up to date yang mempengaruhi turnover intention sesuai kondisi lokasi penelitian. Penelitian hanya memilih satu lokasi penelitian hanya di PT BPR Tish. Kedepan dapat dikembangkan dengan memilih lokasi lebih dari satu. Sampel diambil dalam satu waktu tertentu (cross section) sedangkan lingkungan cepat berubah, sehingga penelitian ini penting dilakukan di masyarakat lainnya dengan menambahkan indikator pengaruh lainnya.

\section{SIMPULAN DAN SARAN}

Berdasarkan pada pembahasan pada bab-bab sebelumnya, maka adapun hal-hal yang dapat disimpulkan yaitu leader member exchange berpengaruh positif dan signifikan terhadap turnover intention karyawan pada PT BPR Tish di Kabupaten Gianyar, artinya penerapan leader member exchange yang terjadi akan mampu mempengaruhi tingkat turnover intention karyawan. Empowerment berpengaruh negatif dan signifikan terhadap turnover intention karyawan pada PT 
BPR Tish di Kabupaten Gianyar, artinya pelaksanaan empowerment akan mampu menurunkan tingkat turnover intention karyawan. Talent management berpengaruh negatif dan signifikan terhadap turnover intention karyawan pada PT BPR Tish di Kabupaten Gianyar, artinya penerapan talent management akan mampu menurunkan tingkat turnover intention karyawan.

Berdasarkan simpulan, saran-saran yang dapat diberikan kepada manajemen PT BPR Tish dalam menghadapi masalah penerapan leader member exchange diperusahaan sedapat mungkin melakukan diskusi yang dipimpin oleh atasan dengan karyawan untuk menghadapi masalah-masalah yang terjadi diperusahan, menghadapi masalah pelaksanaan empowerment, perasaan saling menghargai satu sama lain antara karyawan dan atasan, hal yang harus dilakukan sedapat mungkin melakukan diskusi yang dipimpin oleh atasan dengan karyawan untuk menghadapi masalah-masalah yang terjadi diperusahan, seperti menekan kredit macet, menjaga angka simpanan dan laba dengan mencari solusinya secara bersama-sama dalam mengeluarkan pendapat yang saling menghargai sehingga terciptanya hubungan yang harmonis dan mampu menekan turnover intention. Selain itu sebagai pimpinan perusahaan harus mengajarkan karyawan untuk bekerja cerdas dan cepat dengan mengajarkan budaya kerja yang baik sehingga karyawan bekerja kembali dengan semangat. Masalah karyawan mengenai pelaksanaan talent management, perusahaan harus terus berinovasi dengan mengembangkan talent management sebagai dasar mendidik dan mengembangkan bakat karyawan sehingga karyawan merasa diberikan kesempatan untuk berkarir dan mengurangi tindakan untuk melakukan turnover 
intention dari perusahaan. Manajemen PT BPR Tish dalam menghadapi masalah karyawan mengenai turnover intention karyawan banyak dipengaruhi oleh tingkat pendidikannya, seperti pendidikan diploma yang lulusan teknik tidak mengerti dengan sistem dan prosedur marketing, lulusan akuntansi S.1 ditempatkan dibagian dana, jadi dapat dikatakan manajemen PT BPR Tish menempatkan orang hanya berdasarkan kebutuhan perusahaan, tidak mempertimbangkan latarbelakang pendidikannya ini yang perlu dievaluasi oleh manajemen dan pimpinan kedepan agar mampu memberi tempat kepada karyawan "The right man on the right place" sehingga mampu menekan tindakan turnover intention.

\section{REFERENSI}

Aiza, H. R. dan S. A. Abdus. (2013). Impact of Talent Management and Employee Turnover Intention on Organizational Effecincey- A Case on Telecommunication Sector of Pakistan. International Journal Sci.Int (Lahore), 25(3), 655-660.

Alean, K. H. S. (2014). Pengaruh Kecerdasan Emosional dan Leader Member Exchange (LMX) Terhadap Organizational Citizenship Behavior dengan Kepuasan Kerja Sebagai Variabel Mediasi. Tesis Universitas Sebelas Maret Jakarta.

Amrit, C. S. (2012). An Examination of the Relationship Between LeaderMember-Exchange (LMX) Agreement and the Work Outcomes of Hospitality Employees. International Journal of Hospitality and Tourism, 5(1), 134-146.

Ayu, K. S. (2016). Analisis Pengaruh Manajemen Talenta dan Global Midnset Terhadap Kinerja Karyawan dan Turnover Intention dengan Komitmen Organisasi Sebagai Variabel Intervening (Studi Pada Karyawan PT. Cipta Busana Mandiri Demak). Jurnal Diponegoro of Management, 5(3), 1-15.

Azeez, R. O., F. I. Jayeoba., A. O. Adeoye. (2016). Job Satisfaction, Turnover Intention and Organizational Commitment. Journal of Management Research, 8(2), 102-114. 
Devito, A. J. (2011). Komunikasi Antarmanusia. Tanggerang Selatan: Karisma Publishing Group

Erin, A. W. dan M. S. Eddy. (2013). Pengaruh Leader Member Exchange Terhadap Kepuasan Kerja, Motivasi Kerja dan Komitmen Organisasional Karyawan Departemen Penjualan Pada PT. X. Jurnal Agora, 1(1), 1-10.

Frans, S. (2015). Pengaruh Leader Member Exchange dan Pemberdayaan melalui Mediasi Komitmen Organisasional Terhadap Kinerja (Studi Pada Kantor Notaris di Provinsi Jawa Tengah). Jurnal Ekonomi dan Kewirausahaan, $3(1), 1-12$.

Fedelis, F. (2014). The Impact of Leader-Member Exchange, Employee Empowerment and Affective Commitment on TRNC Hotel and Restaurant Workers: Implications for Retention. International Journal Hospitality and Tourism, 2(3), 1-30.

Iqra, M. W. S. S. (2014). The relationship of Turnover intention with job satisfaction, job performance, Leader member exchange, Emotional intelligence and organizational commitment. International Journal of Learning \& Development, 4(2), 242-256.

Japie R. V. dan W. S. Marius. (2011). Psychological Empowerment, Work Engagement and Turnover Intention: The Role of Leader Relations and Role Clarity in a Financial Institution. Journal of Psychology in Africa, 21(3), 405-412.

Jochan, H. (2015). Pengaruh Leader-Member Exchange (LMX) dan Beban Kerja Terhadap Moral Kerja. Tesis. Universitas Gunadarma.

Kamus Bahasa Indonesia. 2008. Jakarta, Balai Pustaka

Kenneth J. H., R. W. Anthony., dan K. K. Michele. (2009). Leader-member Exchange and Empowerment: Direct and Interactive Effects on Job Satisfaction, Turnover Intentions, and Performance. Journal of The Leadership Quarterly, 20(1), 371-382.

Kharismawati, D. A. P. dan I. G. A. Manuati Dewi. (2016). Pengaruh Komitmen Organisasional, Dukungan Sosial, dan Iklim Etika terhadap Turnover Intention. Jurnal Manajemen Unud, 5(2), 1368-1398. 
Liesl D. P. (2010). The Relationship Between Percieved Talent Management Practices, Perviceived Organization Support (POS) Perceived Supervisor Support (PSS) and Intention To Quit Amongst Generation Employee's in The Recruitment Sector. International Journal of Business and Management, 3(2), 32-75.

Luthans, F. (2011). Perilaku Organisasi, Edisi kesepuluh, Penerbit Andi Offset.

Mahmut, O., O. Demirtas., dan T. Kurt. (2015). The Effect of Leader-Member Exchange (LMX) on Turnover Intentions and Organizational Citizenship Behavior The Mediating Role of Meaningful Work. International Journal of Management and Innovation, 5(6), 710-719.

Monica, V., M. Kusumo., dan E. W. Kartika. (2015). Analisa Pengaruh Leadermember Exchange Terhadap Turnover Intention Dengan Kepuasan Kerja Sebagai Variabel Mediator di Restoran "X" Surabaya. Jurnal Ekonomi dan Kewirausahaan, 3(1), 154-165.

Muhammad, S. A., dan A. Awais. (2016). Effects of Leader-member Exchange, Interpersonal Relationship, Individual Feeling of Energy and Creative Work Involvement Towards Turnover Intention: A Path Analysis Using Structural Equation Modeling. Asian Academy of Management Journal, 21(2), 99-133.

Munish, R. A. (2017). Employee Engagement \& Retention: A Riview of Leterature. International Journal of BRIC Business Research, 6(1), 1-19.

Natalia, H., D. V. Knippenberg and S. Giessner. (2010). Leader Empowering Behaviour: The Leader's Perspective. British Journal of Management, 21(3), 701-716.

Plessis, L. D. (2015). The Management Side Of Talent: Causal Implications For The Retention Of Generation Y Employees. The Journal of Applied Business Research, 31(5), 1767-1780.

Rajkumar, P. dan G. Bhuvaneswari. (2016). Employee Empowerment and Employee Turnover Intention-an Empirical Analysis in Life Insurance Sector. International Journal Business Review, 13(8), 6355-6367.

Rivai, V. (2006). Kepemimpinan dan Perilaku Organisasi. Jakarta : PT. Raja Grapindo Persada.

Robbins, S. P. and T. A. Judge. (2007). Perilaku Organisasi, Edisi Kedua belas, Jakarta: Salemba Empat.

Robbins, S. P. (2011). Perilaku Organisasi, Jilid I, PT.Prenhallindo, Alih Bahasa: Hadyana Pujaatmaka, Jakarta. 
Titiksa, I. B. P. dan I. M. Artha. (2016). Pengaruh Leader-Member Exchange, Role Stress dan Perceived Organizational Support terhadap Turnover Intention Karyawan. Jurnal Manajemen Unud, 5(10), 6174-6200.

Titis, S., A. M. Mochammad., dan T. W. Afrianty. (2016). Pengaruh Komitmen Organisasional Terhadap Turnover Intention (Survei pada Karyawan Hotel Swiss-Belinn Malang). Jurnal Administrasi Bisnis, 40(2), 177-186.

Senge, P. (1990). The Fifth Discipline. New York, NY: Doubleday

Simon, C. H. dan D. Y. Chan. (2016). The Impact of Leader-member Exchange (LMX) and Empowerment on Employee Voice Behavior. Nang Yan Business Journal, 4(1), 44-55.

Sugiyono. (2013). Metode Penelitian Bisnis. Bandung: CV Alfabeta.

Suyana, U. M. (2016). Buku ajar Aplikasi Analisis Kuantitatif. Denpasar: Fakultas Ekonomi Universitas Udayana.

Urbancová, H. dan V. Lucie. (2015). Investigating Talent Management Philosophies. Journal of Competitiveness, 7(3), 3-18.

Vorya, J., M. A. Moradi., dan M. Ahanchi. (2013). An examination of the relationship between empowerment and organizational commitment (Case study Kurdistan province electric staff). International Journal of Contemporary Research in Business, 4(2), 860-868.

Zulkarnain, S. H. (2014). Peranan Komitmen Organisasi dan Employee Engagement terhadap Kesiapan Karyawan untuk Berubah. Jurnal Psikologi, 4l(1), 19-35. 